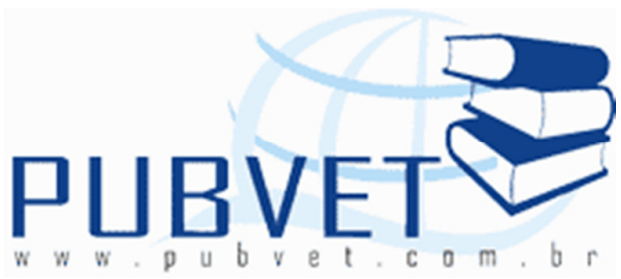

PUBVET, Publicações em Medicina Veterinária e Zootecnia.

\title{
Manejo de pastagens e sistemas alternativos para vacas de leite na região tropical
}

Camila da Silva Souza ${ }^{1}$, Vagno Júnior de Oliveira ${ }^{1}$, Joab Vinícius Martins de Siqueira², Amorésio Souza Silva Filho ${ }^{3}$, Wanderson José Rodrigues de Castro ${ }^{3}$, Angela Aparecida da Fonseca ${ }^{3}$, Marcos Antônio de Oliveira ${ }^{4}$, Letícia de Fátima Carvalho ${ }^{5}$

${ }^{1}$ Zootecnista, Universidade do Estado de Mato Grosso, Campus Universitário de Pontes e Lacerda.

${ }^{2}$ Agrônomo, Universidade do Estado de Mato Grosso.

${ }^{3}$ Mestrando em Ciência Animal, Universidade Federal de Mato Grosso, Campus Cuiabá.

${ }^{4}$ Mestrando em Aquicultura no Centro de Aquicultura da UNESP

${ }^{5}$ Professora do Departamento de Zootecnia da Universidade do Estado de Mato Grosso (UNEMAT), Rodovia 174, km 209, caixa postal 181, Pontes e Lacerda MT.

\section{Resumo}

A criação de bovinos de leite a pasto é a atividade mais adotada por pequenos produtores no Brasil, em sua maioria o sistema funciona quase sem investimentos, por isso se faz necessário à implantação de sistemas de manejo de pastagem que tem como objetivo a diminuição das áreas de implantação de pastagens e a conservação de matas fechadas que antes eram utilizadas para 
a formação de novas pastagens. Também se faz necessário à escolha de forrageiras de melhor qualidade de acordo com o sistema utilizado e também com as exigências dos animais. Os diferentes tipos de pastejo veem sendo empregados na tentativa de diminuir custos de produção e sem que ocorra queda na produção leiteira. Com esse mesmo objetivo pode-se fazer a adição de co-produtos oriundos da indústria agrícola para que possam auxiliar no manejo alimentar de vacas leiteiras, objetivando o fornecimento de fontes de proteína que antes eram descartadas sem empregabilidade, e que hoje se tornaram uma fonte sustentável de alimentação animal.

Palavras-chave: sistema de pastejo, co-produtos, preservação, pastagens.

\title{
Management of pastures and alternative systems for milk cows in tropical region
}

\begin{abstract}
The creation of dairy cattle on pasture is more activity adopted by small farmers in Brazil, mostly it works almost without investment, so it is necessary to implement systems of pasture management that aims at decreasing the area deployment of pasture and conservation of closed forests that were once used for the formation of new pastures. It is also necessary to choose the best quality forage according to the system used and also with the requirements of the animals. The different types of grazing see being employed in an attempt to reduce production costs and without the occurrence of reduced milk production. With this same goal can make the addition of co-products from the agricultural industry so that they can assist in feeding management of dairy cows, aiming to provide protein sources that were previously discarded without employability, and that have now become a source sustainable feed.
\end{abstract}

Keywords: grazing, co-products, preservation, pastures. 
SOUZA, C.S. et al. Manejo de pastagens e sistemas alternativos para vacas de leite na região tropical. PUBVET, Londrina, V. 8, N. 15, Ed. 264, Art. 1756, Agosto, 2014.

\section{INTRODUÇÃO}

A produção de bovinos leiteiros a pasto no Brasil é caracterizada pelo baixo custo, visto que o país apresenta condições favoráveis para a produção de forragens principalmente durante o período das águas.

Quando bem manejadas as pastagens tropicais possuem a capacidade de elevar os níveis de produção de leite principalmente nas épocas favoráveis para seu desenvolvimento, suprindo assim as necessidades dos animais em nutrientes essenciais no processo de produção (GOMIDE et al., 2007).

A alimentação de vacas em lactação chega representar 40 a $60 \%$ do custo de produção de leite, dentro deste contexto, novas alternativas de produção a pasto e sistemas de alimentação eficientes que visa utilizar menos insumos e mão de obra, torna-se uma alternativa interessante tanto do ponto de vista econômico como ambiental (PACIULLO, 2005).

Sendo assim, objetivou-se com essa revisão apresentar os sistemas de pastejo e alternativas que visam tornar o sistema de produção de bovinos leiteiros a pasto eficiente e sustentável.

\section{Importâncias do manejo de pastagem na produção de leite}

Frequentemente as plantas forrageiras são a única fonte de nutrientes essenciais para o crescimento, reprodução e saúde do rebanho. Devido a estes fatores, se tem a importância de se manejar corretamente a pastagem, levando em consideração, a tentativa de aumentar a produção e a eficiência de uso da forragem (GOMIDE e GOMIDE 1999).

São vários os fatores que influenciam a produção leiteira podemos citar o consumo diário de matéria seca, o valor nutritivo da forragem e a genética da vaca. Portanto, é de suma importância que se tenha um correto manejo das pastagens para que se possa garantir uma máxima produção, em consequência disso um alto valor nutritivo da forragem imprimindo assim nas vacas um significativo volume produtivo (VEIGA, 2005). 
SOUZA, C.S. et al. Manejo de pastagens e sistemas alternativos para vacas de leite na região tropical. PUBVET, Londrina, V. 8, N. 15, Ed. 264, Art. 1756, Agosto, 2014.

\section{Taxa de lotação e oferta de forragem para vacas leiteiras}

A taxa de lotação $(T L)$ correspondeà unidade animais por unidade de área, ou numero de animais por hectare, esse termo não é muito correto visto que na propriedade existem animais de diferentes categoria com pesos variáveis desde animais de $100 \mathrm{Kg}$ a animais com mais de $440 \mathrm{Kg}$ (NETO, 1993).

Segundo o mesmo autor é de suma importância permitir que as vacas possam selecionar a forragem ao pastejar, o qual ira satisfazer seu apetite, tanto em qualidade quanto em quantidade, aumentando assim sua produtividade.

Peterson (1961) citado por Tibo (1997) relata que a intensidade ótima de pastejo é caracterizada como sendo o ponto adequado de utilização das pastagens, o qual permite um equilíbrio entre a produção animal e a produção da planta forrageira.

Experimento realizado por Olívio et al. (1992), comparando a produção do capim elefante e o capim sectária durante o período das águas, constataram que o capim elefante se mostrou mais resistente a altas taxas de lotação e maior produção de unidade por área, mas a produção animal por área se mostrou semelhante nos dois tratamentos. Durante as avaliações a menor produção para o capim elefante foi de $10.45 \mathrm{Kg}$ de leite/vaca, e a maior produção foi de $18,67 \mathrm{Kg}$ de leite/vaca, enquanto que a menor produção do capim sectária foi de $11,72 \mathrm{Kg}$ de leite/vaca e a maior produção foi de $18,6 \mathrm{Kg}$ de leite/vaca. Já a taxa de lotação do capim elefante foi de 4,24 UA/ha, e do capim sectária foi de 1,9 UA/ha.

Na tabela 1 pode ser encontrada a resposta das pastagens, manejadas extensivamente, e a pressão de pastejo (lotação animal) nas condições regionais (VEIGA e TOURRAND, 2001). 
SOUZA, C.S. et al. Manejo de pastagens e sistemas alternativos para vacas de leite na região tropical. PUBVET, Londrina, V. 8, N. 15, Ed. 264, Art. 1756, Agosto, 2014.

Tabela 1. A resposta das pastagens, manejadas extensivamente, a pressão de pastejo (lotação animal) nas condições regionais.

\begin{tabular}{|c|c|c|}
\hline $\begin{array}{l}\text { Lotação } \\
\text { Animal } \\
\text { (UA/ha) }\end{array}$ & Resposta da Pastagem & $\begin{array}{c}\text { Reflexo na Produção } \\
\text { animal }\end{array}$ \\
\hline $\begin{array}{c}\text { Baixa } \\
(<0,75)\end{array}$ & $\begin{array}{l}\text { Acumulo de forragem de baixa } \\
\text { qualidade, porem os animais } \\
\text { podem selecionar. } \\
\text { Maior persistência da pastagem } \\
\text { e maior concorrência com as } \\
\text { plantas daninhas }\end{array}$ & $\begin{array}{l}\text { A produção por animal é } \\
\text { alta, porem a produção } \\
\text { por hectare é baixa. }\end{array}$ \\
\hline $\begin{array}{c}\text { Media } \\
(0,75 \text { a } \\
1,25) \\
\end{array}$ & Situação intermediaria & Situação intermediaria \\
\hline $\begin{array}{c}\text { Alta } \\
(>1,25)\end{array}$ & $\begin{array}{l}\text { A quantidade de forragem } \\
\text { embora de boa qualidade tende } \\
\text { a diminuir }\end{array}$ & $\begin{array}{l}\text { A produção por hectare é } \\
\text { baixa, porem a produção } \\
\text { por hectare é alta. } \\
\text { A partir de certo nível de } \\
\text { lotação, a produção por } \\
\text { animal e por hectare é } \\
\text { baixa. }\end{array}$ \\
\hline
\end{tabular}

$\mathrm{UA}=$ Equivalente a um animal de $450 \mathrm{~kg}$ de peso vivo. Fonte: Veiga e Tourrand(2001).

\section{Sistemas de pastejo utilizados para vacas de leite}

O sistema de pastejo ideal corresponde aquele que permite maximização tanto da produção animal como da forragem, o qual visa melhor utilização do pasto e maior produtividade animal, sem afetar o crescimento e a rebrota da planta forrageira (Neto, 1993).

Gardner e Alvim (1985) relatam que ao aumentar a quantidade de forragem para pastejo, ocorre maior predisposição de forragem de baixa qualidade. Portanto, os autores recomendam utilizar a forragem no ponto que haja maior quantidade de massa verde com melhor qualidade de nutrientes, o qual pode ser mais bem observado na figura 1. 


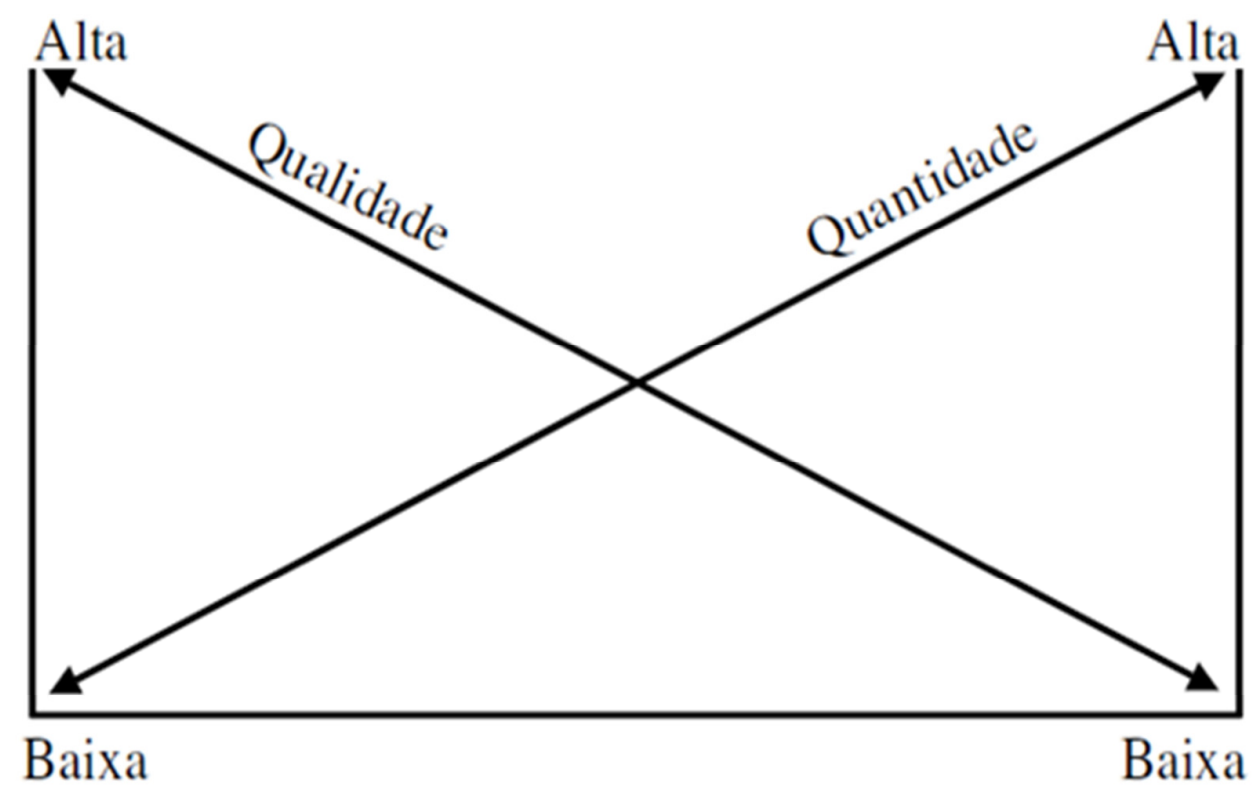

Figura 1. Relação da quantidade e da qualidade da forragem. Fonte: Gardner e Alvim, 1985.

\section{Lotação Rotacionada}

A principal vantagem de se utilizar este sistema de pastejo é tornar possível um maior controle sobre o pasto, permitindo assim, uma definição de quando e por quanto tempo os animais serão colocados ou retirados de um determinado piquete (BALSALOBRE e SANTOS, 2004).

O sistema de pastejo com lotação rotacionada pode ser definido como a mudança frequente dos animais de um piquete para outro, dentro do mesmo tipo de pastagem (MARASCHIN, 2001).

Aguiar (2007) ressalta que as maiores vantagens desse sistema é conferir maior uniformidade de pastejo, o qual permite aumentar a taxa de crescimento da planta forrageira e possibilitar maior capacidade de suporte do pasto aumentando desta forma o rendimento dos animais por área.

\section{Pastejo em faixas}

Neste sistema o manejo deve ser realizado com o auxílio de cercas elétricas, tendo como principal função o não acesso dos animais a áreas já pastejadas anteriormente (RODRIGUES e REIS, 2005). 
SOUZA, C.S. et al. Manejo de pastagens e sistemas alternativos para vacas de leite na região tropical. PUBVET, Londrina, V. 8, N. 15, Ed. 264, Art. 1756, Agosto, 2014.

O método de pastejo em faixas pode ser definido pelo acesso do animal a uma área de pastagem limitada ainda não pastejada, aonde o pastejo vai sendo realizado de acordo coma movimentação das cercas em faixas da pastagem. Esse método é bem eficiente para vacas leiteiras, pois permite melhor utilização da forragem (PEDREIRA et al., 2002).

\section{Pastejo diferido}

Pode-se definir por pastejo diferido, o sistema onde se veda uma determinada área para que não ocorra à entrada de animais ate que a pastagem finalize seu crescimento, o que permite acumular forragem em forma de feno em pé, para que seja disponibilizado para os animais nos períodos em que a oferta de foragem se torna critico (PEDREIRA et al., 2002).

O pastejo diferido pode ser caracterizado como uma pratica de baixo custo de execução e fácil implantação (OLIVEIRA e FARIA 2006). O mesmo autor ressalta que apesar de ser uma técnica que garante a disponibilidade de alimento nos períodos de estacionalidade das pastagensessa técnica faz com que o valor nutritivo da forragem seja reduzido. Maraschin (2001) cita que o pastejo diferido possui como vantagem a não necessidade de investimentos com tecnologias utilizadas na conservação da forragem.

\section{Irrigação}

No território brasileiro, existe uma grande diversificação, quando levado em consideração os fatores climáticos, o que provoca a estacionalidade da planta forrageira, esta diversificação se deve principalmente as diversas regiões do paíspossuir altitude e latitude diferentes. Na tentativa de se amenizar os efeitos do período de seca, o sistema de irrigação pode ser utilizado, desde que os fatores de luminosidade e temperatura não sejam limitantes (PACIULLO, 2005).

Pedreira(1972) realizou um trabalho utilizando capim Pangola (Digitaria decumbens), capim Colonião (Panicummaximum), capim Jaraguá (Hyparrhenia rufa (Nees) Stapf) e capim Gordura (Melinisminutiflora), para verificar a taxa 
SOUZA, C.S. et al. Manejo de pastagens e sistemas alternativos para vacas de leite na região tropical. PUBVET, Londrina, V. 8, N. 15, Ed. 264, Art. 1756, Agosto, 2014.

de crescimento diário nos diferentes meses do ano sendo possível assim identificar os períodos de estacionalidade das diferentes forrageiras (Figura 2).

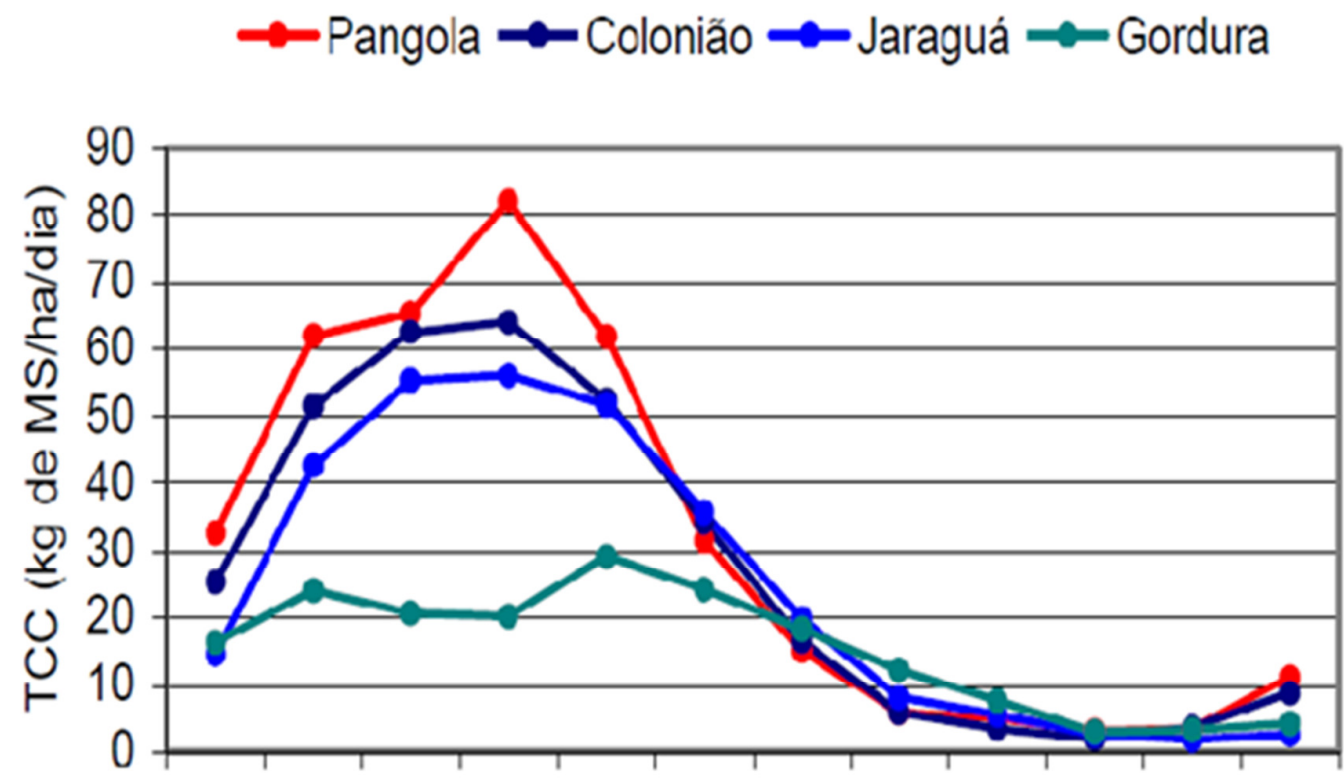

Out Nov Dez Jan Fev Mar Abr Mai Jun Jul Ago Set

Figura 2. Taxas de crescimento diário da cultura (TCC) dos capins colonião, Jaraguá, gordura e pangola, em Nova Odessa, SP. Fonte: adaptado de Pedreira, 1972.

Quando o déficit de forragem não for levado em consideração durante a estacionalidade, a produção animal acompanha a curva de produção observada na figura acima. Tendo seu pico de produção entre os meses de novembro a fevereiro em consequência do período chuvoso, e um decréscimo da produção no período da seca (ANDRADE, 2000).

O mesmo autor cita que entre os sistemas de irrigação mais utilizados está à irrigação por superfície, o qual utiliza um sistema de sulcos ou mesmo a inundação. 
SOUZA, C.S. et al. Manejo de pastagens e sistemas alternativos para vacas de leite na região tropical. PUBVET, Londrina, V. 8, N. 15, Ed. 264, Art. 1756, Agosto, 2014.

\section{Estimativa de lâmina de irrigação}

São necessários alguns parâmetros para que seja estimada a lâmina de irrigação da pastagem, que são eles: saturação, que é medida através da água que é drenada para baixo da zona radicular da planta, ou seja, não será mais disponibilizada para a mesma; capacidade de campo, que é a quantidade máxima de água que pode ser retida pelo solo, sem que o mesmo sofra danos em relação ao sistema; ponto de murcha permanente definido através de um determinado limite, ou seja, quando a água presente no solo já não esta mais disponível para a planta (ALENCARet al., 2009).

\section{Algumas espécies forrageiras utilizadas na nutrição de vacas leiteiras}

\section{Gênero Brachiaria}

A grande maioria das pastagens cultivadas no Brasil é constituída pelo gênero Brachiarias sendo estimadas em cerca de 180 milhões de hectares correspondendo a $85 \%$ do total ocupado por pastagens no Brasil. Esse gênero possui mais de 100 espécies encontradas em regiões tropicais e subtropicais, sendo originário da África (OLTRAMARI e PAULINO, 2009).

O capim marandu ou "Braquiarão" ocupa a maior área do Brasil, chegando a $60 \%$ das áreas destinadas a pastagens no brasil. É uma espécie de grande rusticidade e que apesar disso ainda apresenta elevado grau de degradação principalmente em pasto mau manejos onde o nutriente não é fornecido de forma correta. Sob pastejo continuo trabalhos e pesquisa vem sendo realizados na tentativa de estabelecer uma faixa de utilização ótima entre 20 a $40 \mathrm{~cm}$ de altura do pasto, quando manejado com alturas inferior a essa faixa são observados sinais de degradação (GIMENES, 2012).As plantas desse gênero podem ser definidas como sendo de grande flexibilidade de uso e de manejo, a grande maioria das espécies é tolerante a uma série de fatores limitante e a condições restritivas de uso.Oltramari e Paulino (2009) 
SOUZA, C.S. et al. Manejo de pastagens e sistemas alternativos para vacas de leite na região tropical. PUBVET, Londrina, V. 8, N. 15, Ed. 264, Art. 1756, Agosto, 2014.

recomendam um período de descanso entre 28 a 42 dias, e resíduo pós pastejo de 20 a $30 \mathrm{~cm}$ em sistema de pastejo com lotação rotacionada.

\section{Gênero Pennisetum}

Dentre as espécies mais utilizadas desse gênero na produção leiteira destaca-se o capim elefante (Pennisetumpurpureum, Schum.) por ser uma espécie considerada de alto valor de produção, sendo utilizada recentemente como espécie promissora na produção de leite a pasto. O capim elefante possui como característica principal o aumento na qualidade e na quantidade de leite produzido, desta forma reduz os custos da produção leiteira (FONSECAet al., 1998).

Coseret al.(2000), verificaram que a produção media diária de vacas mantidas em pastagens de capim elefante sob lotação rotacionada com período de descanso de 30 dias e período de ocupação de 1, 3 e 5 dias, foram similares.

Os mesmos autores ressaltam que o capim elefante apresenta-se bem resistente à seca, doenças e pragas (exceto a cigarrinha), o que permite fácil adaptação aos diferentes climas do Brasil, tendo seu melhor desempenho sob lotaçãorotacionada, no entantopara que se obtenha máxima produção do capim elefante deve-se levar em conta a altura ideal de corte bem como adubação química e orgânica.

\section{Sistemas alternativos para o período da seca nas regiões tropicais}

Devido ao grande demanda por produtos oriundos da bovinocultura leiteira, faz-se necessário a busca por alternativas que minimizem os custo de produção e a degradação ao ambiente com as imensas plantações de grãos. O uso de resíduos agroindustriais na alimentação animal proporciona um amento na produção e uma diminuição nos impactos ambientais que possam ser provocados devido à falta de destino adequada para os resíduos (SOUZAet al., 2011). 
SOUZA, C.S. et al. Manejo de pastagens e sistemas alternativos para vacas de leite na região tropical. PUBVET, Londrina, V. 8, N. 15, Ed. 264, Art. 1756, Agosto, 2014.

\section{Cana de açúcar e Silagem de cana}

Grande número de produtores de leite utilizaa cana-de-açúcar (Saccharumspp) como fonte de volumoso principalmente no período seco do ano, sendo este alimento ofertado a vacas mestiças de baixa a media produção (FERNANDESet al., 2001).

Sua utilização vem se destacando na alimentação animal pelo seu baixo custo de produção, e grande quantidade de matéria seca produzida por área.

Outra vantagem da utilização da cana-de-açúcar como recurso forrageiro se dapelo fato da cana manter seu valor nutritivo por um período de tempo relativamente longo, tendo de 12 a 18 meses como sendo os melhores valores obtidos quando comparado com outras gramíneas (PRESTON, 1986 citado por FERNANDESet al., 2001).

Segundo Corrêa(2001) citado por Camposet al.(2009), dietas que utilizam como volumoso principal a cana-de-açúcar devem conter uma maior inclusão de concentrados proteicos para que se possam suprir as exigências dos animais devido ao baixo teor de proteína que a cana apresenta.

Mendonça et al. (2004) citado pelo mesmo autor também observaram que a produção de leite para as dietas à base de cana-de-açúcar como volumoso, independente do nível de uréia ou da relação volumoso:concentrado, foi $2,77 \mathrm{~kg}$ menor que a dieta à base de silagem de milho. A menor produção de leite para as dietas com maior participação de cana-de-açúcar pode ser explicada pelo menor consumo de matéria seca, o que resulta em menor consumo de nutrientes (Tabela 2). 
SOUZA, C.S. et al. Manejo de pastagens e sistemas alternativos para vacas de leite na região tropical. PUBVET, Londrina, V. 8, N. 15, Ed. 264, Art. 1756, Agosto, 2014.

Tabela 2. Influência da cana de açúcar no consumo e produção leiteira em comparação com outros alimentos.

\begin{tabular}{|c|c|c|c|c|c|}
\hline Variáveis & $\begin{array}{c}\text { Cana } \\
\text { fresca }\end{array}$ & $\begin{array}{c}\text { Cana fresca+ } \\
\text { sil. de milho }\end{array}$ & $\begin{array}{l}\text { Sil de } \\
\text { cana }\end{array}$ & $\begin{array}{l}\text { Sil. de } \\
\text { milho }\end{array}$ & Epm \\
\hline $\begin{array}{l}\text { Consumo de MS } \\
\text { (Kg/dia) }\end{array}$ & $22,32 b$ & $23,47 \mathrm{a}$ & $23,47 a$ & $21,58 \mathrm{c}$ & 0,12 \\
\hline $\begin{array}{l}\text { Produção de leite } \\
\text { (Kg/dia) }\end{array}$ & 24,25 & 25,119 & 24,42 & 25,54 & 0,75 \\
\hline $\begin{array}{l}\text { Produção de leite } \\
4 \% \mathbf{G}^{1}\end{array}$ & 22,10 & 23,02 & 22,13 & 24,02 & 0,73 \\
\hline
\end{tabular}

${ }^{1}$ produção de leite corrigida para $4 \%$ de gordura.

Letras diferentes, na mesma linha diferem estatisticamente entre si $(p>0,05)$. Fonte: Queiroz (2006).

\section{Resíduo de cervejaria}

O resíduo de cervejaria é mais uma opção dentre as diversas alternativas de utilização paraa produção animal no Brasil, sua utilização se deve principalmente pela sua qualidade nutricional e pela sua disponibilidade durante todo o ano. O resíduo úmido de cervejaria é obtido no processo de fabricação de cerveja,em que o malte de cevada é utilizado como matéria prima juntamente com mistura de outros cereais como milho e arroz (SOUZA etal., 2011).

Segundo Velasco et al. (2006), a matéria prima utilizada pelas industrias de cervejaria do pais é constituída pelo malte de cevada e também por outros cereais.

Geronet al.(2010), relata que os diferentes ingredientes utilizados na fabricação de cerveja podem causar variações químicas bromatológica no resíduo úmido de cervejaria, por isso se faz necessário a análise do produto a ser utilizado (Tabela 3 ). 
SOUZA, C.S. et al. Manejo de pastagens e sistemas alternativos para vacas de leite na região tropical. PUBVET, Londrina, V. 8, N. 15, Ed. 264, Art. 1756, Agosto, 2014.

Tabela 3. Composição bromatológica de resíduo úmido de cervejarias proveniente de diferentes indústrias.

\begin{tabular}{lcccc}
\hline Nutriente & \multicolumn{4}{c}{ Indústrias } \\
\cline { 2 - 5 }$(\%)$ & Brahma & Kaiser & Schincariol & Skol \\
\hline MS & 15,6 & 9,2 & 12,3 & 14,7 \\
PB & 31,8 & 26,0 & 27,6 & 31,7 \\
FB & 15,8 & 18,9 & 14,1 & 14,9 \\
FDN & 43,8 & 54,0 & 44,5 & 47,8 \\
FDA & 21,3 & 26,5 & 20,9 & 25,9 \\
NDT & 74,0 & 69,4 & 70,6 & 68,9 \\
\hline
\end{tabular}

Fonte: Aronovich (1999).

Cardoso et al.(1982) e Velasco et al. (2006), verificaramque a produção de leite de vacas alimentadas com silagem de sorgo e suplementadas com $42,9 \%$ e $85,9 \%$ de resíduo úmido de cervejaria no concentrado,apresentaram maior produção de leite.

\section{Casca de soja}

Oliveira etal. (2007), trabalhando com vacas holandesas, puras e mestiças, avaliou o efeito da substituição do milho por casca de café ou casca de soja na dieta sobre o consumo e a digestibilidade dos nutrientes, a produção e composição do leite. Foram avaliadas três dietas à base de canade-açúcar e com $60 \%$ de concentrado na MS: controle (sem casca de soja ou de café), $25 \%$ e outra com $50 \%$ de substituição do milho pela casca de café e casca de soja, respectivamente, os autores constataram que as dietas foram suficientes para atender às exigências para produção de leite de $20 \mathrm{~kg} / \mathrm{dia}$. Sendo assim os autores concluíram que dietas à base de cana-de-açúcar para vacas com produção de $20 \mathrm{~kg}$ de leite/dia, o milho pode ser substituído em $25 \%$ pela casca de café ou em $50 \%$ pela casca de soja, desde que a participação de concentrado seja de $60 \%$.

Pedroso et al. (2007), trabalhando com vacas holandesas no terço médio da lactação, 123 dias em lactação, avaliaram a substituição do milho moído (MM) por casca de soja (CS) em rações contendo silagem de milho como volumoso principal e polpa cítrica como parte da fonte energética. Foram 
SOUZA, C.S. et al. Manejo de pastagens e sistemas alternativos para vacas de leite na região tropical. PUBVET, Londrina, V. 8, N. 15, Ed. 264, Art. 1756, Agosto, 2014.

avaliadas rações com 0, 10 e $20 \%$ de substituição do milho moído por casca de soja na ração. A inclusão de CS nas rações não afetou o consumo de MS $(22,84 \mathrm{~kg} / \mathrm{dia})$, a produção de leite $(28,33 \mathrm{~kg} / \mathrm{dia})$ ou a produção de leite corrigida para $3,5 \%$ gordura $(28,48 \mathrm{~kg} / \mathrm{dia})$. Desta forma os autores concluíram que a substituição do milho moído por casca de soja na alimentação de vacas leiteiras pode ser uma alternativa interessante, desde que o preço do subproduto seja competitivo.

A limitação da inclusão da casca de soja na dieta de bovinos leiteiros se da pelo fato da diminuição nos níveis de energia da dieta total, quando este alimento for substituir grãos de cereais no concentrado, também possui menor estimulo a ruminação e a salivação quando em substituição a alimentos volumosos. Deste modo devem-se respeitar os limites de inclusão da casca para promover o equilíbrio e a produção animal(RIBEIRO JÚNIOR, et al., 2007).

\section{Caroço de Algodão}

Devido ao seu alto teor energético e seu valor nutricional, o caroço de algodão está entre os alimentos que mais se destacam na alimentação alternativa para a bovinocultura de leite, suas características nutricionais se assemelha aos alimentos concentrados (Tabela 4), isso em função a seu grande conteúdo de fibra efetiva, porem devido à presença de substancias como gossipol e aflatoxinas, seu uso na dieta desses animais pode ser inviabilizado (MESSANA et al., 2009).

Vilela et al. (1996), trabalhando com vacas $7 / 8$ Holandês $\times$ Zebu após pico de lactação com produção média diária de $20 \mathrm{~kg}$, alimentadas com silagem de milho associada a quatro rações concentradas contendo 10, 20 e 30\% de Caroço de algodão, concluíram que o caroço de algodão pode ser usado até o nível de $30 \%$ na ração concentrada sem influir no consumo dos nutrientes ou na produção de leite. 
SOUZA, C.S. et al. Manejo de pastagens e sistemas alternativos para vacas de leite na região tropical. PUBVET, Londrina, V. 8, N. 15, Ed. 264, Art. 1756, Agosto, 2014.

Tabela 4. Composição química do caroço de algodão expressa em \% de matéria seca.

\begin{tabular}{lccc}
\hline \multirow{2}{*}{ Nutrientes } & \multicolumn{3}{c}{ Alimento } \\
\cline { 2 - 4 } MS & 89,50 & 90,64 & 92,60 \\
MO & 86,14 & 96,32 & 96,40 \\
PB & 22,69 & 22,62 & 21,03 \\
EE & 12,16 & 18,90 & 21,20 \\
FDN & 30,80 & 46,04 & 44,97 \\
FDA & - & 35,85 & 33,37 \\
NDT & - & 81,92 & 84,33 \\
EB & - & 5,57 & - \\
(Mcal/KgMS) & Paulino et al. & Valadares Filho & Melo et al. \\
\hline Autores & (2002) & et al. (2006) & (2006) \\
\hline
\end{tabular}

MS: matéria seca; MO: Matéria Orgânica; PB: Proteína Bruta; EE: Extrato Etéreo; FDN: Fibra em Detergente Neutro; FDA: Fibra em Detergente Ácido; NDT: Nutrientes Digestíveis Totais; EB: Energia Bruta.

Melo et al. (2006), ao avaliarem o efeito da inclusão do caroço de algodão $(0,6,25,12,50,18,75$ e $25 \%$ da matéria seca da dieta), em dietas à base de palma forrageira sobre o desempenho de vacas da raça Holandesa em lactação, constataram que o caroço de algodão aumentou a produção de leite corrigido para $3,5 \%$ de gordura de 26,53 para $31,68 \mathrm{~kg}$ por dia, e a produção de gordura do leite de 0,86 para 1,09 kg por dia, e observaram que a inclusão do caroço de algodão não afetou, porém, a produção de leite sem correção (31,19 kg por dia).

Sousa et al. (2009) avaliando o comportamento ingestivo, produção e composição do leite de vacas alimentadas com silagem de milho e cana-deaçúcar com caroço de algodão (0, 7 e 14\% de caroço de algodão), com relação volumoso:concentrado de 60:40, observaram que o tratamento com cana-deaçúcar a 7 \% de caroço de algodão fez aumentar o consumo de MS que anteriormente era de $15.5 \mathrm{Kg} /$ dia e passou a ser de $17.1 \mathrm{Kg} / \mathrm{dia}$. Os autores constataram que os maiores consumos resultaram em maiores produção de leite com 19,7 e 20,6 vs $18,6 \mathrm{~kg} /$ dia e de leite corrigido para gordura com 21,1 e 21,6 vs $18,9 \mathrm{~kg} /$ dia, também foram observados maiores produções diárias 
SOUZA, C.S. et al. Manejo de pastagens e sistemas alternativos para vacas de leite na região tropical. PUBVET, Londrina, V. 8, N. 15, Ed. 264, Art. 1756, Agosto, 2014.

de gordura (771 e 781 vs 664 g/dia) e proteína (602 e 625 vs 565 g/dia) pelos dois níveis de inclusão em comparação ao tratamento sem caroço de algodão.

\section{CONSIDERAÇÕES FINAIS}

O manejo das pastagens se faz necessário para que haja uma maior produção de matéria seca sem que haja aumento da área cultivada, preservando assim os recursos naturais, e ao mesmo tempo aumentar a produtividade animal.

A escolha do melhor sistema deve ser feita de acordo com a necessidade de cada produtor, pois independente do sistema escolhido o manejo da forrageira deve se o mais correto possível respeitando suas características morfogênicas fazendo com que a mesma seja de qualidade, imprimindo assim para o animal uma maior eficiência produtiva.

\section{REFERÊNCIAS}

AGUiAR, A. de P. A. Manejo de Pastagens. Viçosa: CPT, 2007. 380p.

ALENCAR, C. A. B. et al. Irrigação de pastagem: atualidade e recomendações para uso e manejo. Revista Brasileira de Zootecnia, v.38, p.98-108, 2009 (supl. especial).

ANDRADE, C. M. S. de. Produção de bovinos em pastagem irrigada. Universidade Federal de Viçosa, 2000.Disponível em: http://www.forragicultura.com.br/arquivos/Irrigacaopastagens_Revis\%C3\%83\%C2\%A3o.pdf. Acesso em: 12 de setembro de 2012.

ARONOVICH, M. Composição bromatológica e degradabilidade de silagens de resíduo úmido de cervejaria. 1999. 66f. Dissertação (Mestrado em Zootecnia) - Universidade Federal de Lavras, Lavras, MG.

BALSALOBRE, M. A. A.; SANTOS, P, M. Sistemas de pastejo Rotacionado: Divisão da área.Milkpoint. Março de 2004. Disponível em:<http://www.milkpoint.com.br/radartecnico/pastagens/sistemas-de-pastejo-rotacionado-1-divisao-da-area-18548n.aspx>. Acesso em: 12 de setembro de 2012.

CAMPOS. M. M; BORGES, A. L. da C. C; GONÇALVES, L. C.Cana-de-açúcar na alimentação de gado de leite. In: GONÇALVES, L. C; BORGES, I; FERREIRA,P. D. S. Alimentos para Gado de Leite. Belo Horizonte: FEPMVZ, 2009. p. 7-20.

CARDOSO, R.M. et al. Produção de leite de vacas alimentadas com silagen de sorgo suplementada com polpa úmida de cevada. Revista Brasileira de Zootecnia, v.11, p.38-45, 1982.

CÓSER, A.C; MARTINS, C.E.; DERESZ, F. Capim-elefante: formas de uso na alimentação animal. Juiz de Fora, MG: Embrapa Gado de Leite. 2000. 27p. (Embrapa Gado de Leite. Circular Técnica, 57). 
FERNANDES, A. M. et al. Estimativas da produção de leite por vacas Holandesas Mestiças, segundo o sistema CNCPS, em dietas contendo Cana-de-Açúcar com diferentes valores nutritivos. Revista Brasileira de Zootecnia, p. 1350-1357, 2001.

FONSECA, D. M. da. et al. Produção de Leite em Pastagem de Capim-Elefante sob Diferentes Períodos de Ocupação dos Piquetes. Revista Brasileira de Zootecnia, v.27, n.5, p.848-856, 1998.

GARDNER, A.L. e ALVIM, M.J. Manejo de pastagem. EMBRAPA-CNPGL. Coronel Pacheco, MG. 1985.

GERON, L.J.V. et al. Consumo, digestibilidade dos nutrientes, produção e composição do leite de vacas alimentadas com resíduo de cervejaria fermentado. Acta Scientiarum.Animal Sciences, v.32, n.1, p. 69-76, 2010.

GIMENES, F. M. De A. Manejo de pastagens com ênfase em gado leiteiro. Disponivel em: <http://pt.engormix.com/MA-pecuaria-leite/administracao/artigos/manejo-pastagens-comenfase-t1216/124-p0.htm> .acesso em: 20/09/2012.

GOMIDE, C. A. de M.; PACIULLO, D. S. C.; CARNEVALLI, R. A. Considerações sobreo manejo do pastejorotativo de gramíneas tropicais. Juiz de Fora - MG: Embrapa Gado de Leite, 2007 (Comunicado Técnico 53).

GOMIDE, J. A.; GOMIDE, C. A. de M. Fundamentos e estratégias do manejo de pastagens. In: SIMPÓSIO DE PRODUÇÃO DE GADO DE CORTE, 1, 1999, Viçosa. Anais... Viçosa: SIMCORTE, 1999 , p. $179-200$.

MARASCHIN, G. E. Caracterização de sistemas de produção em pastagens. In: SIMPÓSIO SOBRE MANEJO DA PASTAGEM, 18, Piracicaba, 2001. Anais... Piracicaba: FEALQ, 2001, p.160.

MELO A. A. S. et al. Desempenho leiteiro de vacas alimentadas com caroço de algodão em dietas à base de palma forrageira. Pesquisa Agropecuária Brasileira, v.41, p.1165-1171, 2006.

MENDONÇA, S.S. et al. Consumo, digestibilidade aparente, produção e composição do leite e variáveis ruminais em vacas leiteiras alimentadas com dietas à base de cana-de-açúcar. Revista Brasileira de Zootecnia, v.33, p.481-492, 2004.

MESSANA, J. D. et. al. Valor nutritivo do resíduo do processamento do caroço de algodão suplementado com levedura e avaliado em bovinos. RevistaBrasileira de Zootecnia, v.38, n.10, p.2031-2037, 2009.

NETO, M. S.Sistemas de pastejo. $2^{\circ}$ ed. Piracicaba - SP, 1993. 377p.

OLIVEIRA, A. S de et al. Substituição do milho por casca de café ou de soja em dietas para vacas leiteiras: consumo, digestibilidade dos nutrientes, produção e composição do leite. Revista Brasileira de Zootecnia, Viçosa, v.36, n.4, p.1172-1182, 2007.

OLIVEIRA, I. P. DE; FARIA, A. G. DE. Considerações sobre manejo de bovino em sistema de pastejo. Revista EletrônicaFaculdade Montes Belos, v.1, n.1, p. 117-146, 2006.

OLTRAMARI, C. E.; PAULINO, V. T. Forrageiras para gado leiteiro. Nova Odessa, São Paulo, 2009. 22p. (Relatório de Estágio).

PACIULLO, D. S; C, HEINEMANN, A.B; MACEDO, R. de O. Sistemas de produção de leite baseados no uso de pastagens. Revista EletrônicaFaculdade Montes Belos,v.1, n.1, p. 88106, 2005.

PEDREIRA, C. G. S. et al. Sistemas de pastejo na exploração pecuária brasileira. Departamento de Zootecnia, USP-ESALQ, Piracicaba, SP, 2002. Disponível em: <http://www. forragicultura.com.br/arquivos/SISTEMASDEPASTEJONAEXPLORACAOPECUARIAB RASILEIRA.PDF.> Acesso em: 12/10/11. 
PEDREIRA, J.V. Crescimento estacional dos capins colonião (PanicummaximumJacq.), gordura (MelinisminutifloraPal de Beauv), jaraguá (Hyparrhenia rufa (Ness) Stapf) e pangola de Taiwan A-24 (Digitaria pentzii Stent), 1972. 61f. Dissertação (Mestrado) Escola Superior de Agricultura "Luiz de Queiroz", Universidade de São Paulo, Piracicaba.

PEDROSO, A.M. et al. Substituição do milho moído por casca de soja na ração de vacas leiteiras em confinamento. Revista Brasileira de Zootecnia, v.36, p.1651-1657, 2007.

QUEIROZ, O.C.M. Associação de aditivos microbianos na ensilagem e o desempenho de vacas em lactação recebendo silagem de cana-de-açúcar comparada a volumosos tradicionais.Piracicaba: Escola Superior de Agricultura "Luiz de Queiroz",2006. 120p. Dissertação (Mestrado em Ciência Animal e Pastagens) - Escola Superior de Agricultura "Luiz de Queiroz", Piracicaba. 2006.

RIBEIRO JUNIOR, G. De O. et al. Casca de soja na alimentação de gado de leite. In: GONÇALVES, L. C; BORGES, I; FERREIRA, P. D. S. Alimentos para Gado de Leite. Belo horizonte: FEPMVZ, 2009. p. 173-208.

RODRIGUES, L. R. de A.; REIS, R. A. Conceituação e modalidades de sistemas intensivos de pastejo rotacionado. In: SIMPÓSIO SOBRE MANEJO DA PASTAGEM, 14, Piracicaba, 2005. Anais...Piracicaba:FEALQ, 2005, p.1-24.

SOUZA, D. de P. et al. Comportamento ingestivo, consumo e digestibilidade de nutrientes, produção e composição do leite de vacas alimentadas com silagem de milho ou cana-de-açúcar com caroço de algodão. Revista Brasileira de Zootecnia, Viçosa, v.38, n.10, p.2053-2062, 2009.

SOUZA, L. C de. et al. Inclusão do resíduo úmido de cervejaria na dieta de vacas em lactação. In: REUNIÃO ANUAL DA SOCIEDADE BRASILEIRA DE ZOOTECNIA, 48. Belém, Anais...Belém: SBZ: UFRA, 2011, p. 1-3.

TIBO, G. C. Influência da taxa de lotação na produção de bovinos em regime de pasto. Trabalho apresentado como parte das exigências da Disciplina ZOO 650 - Forragicultura. Viçosa - MG, Julho - 1997.

VEIGA, J. B. da.Criação de Gado Leiteiro na Zona Bragantina. Embrapa Amazônia Oriental. Dez. 2005.2 Disponível em: <http://sistemasdeproducao.cnptia.embrapa.br/FontesHTML/Leite/GadoLeiteiroZonaBragantin a/paginas/manejop.htm>. Acesso em: 05 de outubro. 2012.

VELASCO, F. O. et al. Resíduo de cervejaria para gado leiteiro. Alimentos para gado de leite.Belo horizonte: FEPMVZ, 2009. P. 147-159.

VILLELA, S. D. J. et al. Caroço de Algodão para Vacas Leiteiras I. Consumo de Nutrientes, Produção e Composição do Leite. Revista Brasileirade Zootecnia, v. 26, n 2, p. 298, 1996. 